\title{
Bireysel Emeklilik Sistemindeki Şirketlerin Performanslarının Gri İlişkisel Analizle Ölçülmesi ve Bir Uygulama ${ }^{a}$
}

\author{
Gülay Demir ${ }^{b, c}$, Hüdaverdi Bircand, Sinan Dündare
}

\section{Özet}

Bireysel emeklilik sistemi, aktif iş yaşamındaki mevcut standartları emekli olduğunda da sürdürmek için düzenli tasarruf yapma esasına dayanan, gönüllü katılım ile gerçekleşen, devlet katkısıyla desteklenen bir sistemdir. Bu çalışmada Hazine Müsteşarlığı, Sermaye Piyasası Kurulu ve Emeklilik Gözetim Merkezi tarafından gözetim ve denetim altında tutulan 18 tane bireysel emeklilik şirketinin performanslarının ölçümü amaçlanmıştır. Gri İlişkisel Analizin tüm alanlarda rahatlıkla kullanılması ve az veri ile bile çok iyi sonuçlar vermesi nedenleri çalışmanın uygulama kısmı için tercih edilen yöntem olmasını sağlamıştır. Emeklilik ve Gözetim Merkezinin 24.11.2017 tarihli verileri kullanılarak analizler yapılmıştır. Yapılan değerlendirmeler sonucunda Anadolu Hayat ve Emeklilik şirketi performansı en yüksek, Aegon Emeklilik ve Hayat şirketinin performansı en düşük olmuştur.
Anahtar Kelimeler

Bireysel Emeklilik

Gri İlişkisel Analiz

Makale Hakkında

Geliş Tarihi: 15.07.2019

Kabul Tarihi: 10.06.2020

Doi: 10.18026/cbayarsos.592295

\section{Measuring the Performance of Companies in the Private Pension System with Gray Relational Analysis and an Application}

\begin{abstract}
Private pension system is a system that is based on making regular savings in order to maintain the current standards in active work life, is voluntarily participated in, and is supported by the state. In this study, it is aimed to measure the performances of 18 private pension firms which are under supervision and surveillance of Pension Surveillance Center, Capital Markets Board, and Undersecretary of Treasury. The performances of these firms are examined considering five criteria, which are the number of participants, participants' sum of funds, state-supported sum of funds, contribution margin sum of funds, and the number of retired participants. Because the Grey Relational Analysis is easily used in all fields and produces good results even with very few data, it is preferred for the practical application of the study. The analyses are carried out by using the data from Pension Surveillance Center dated 24.11.2017. At the end of evaluations, Anadolu Hayat ve Emeklilik Company was found to be the one with the highest performance and Aegon Emeklilik ve Hayat Company the one with the lowest performance.
\end{abstract}

Keywords

Private Pension

Grey Relational Analysis

About Article

Received: 15.07.2019

Accepted: 10.06 .2020

Doi: 10.18026/cbayarsos.592295

\footnotetext{
a Bu makalenin özeti, 2-3 Mart 2018 tarihleri arasında düzenlenen İstanbul Bilim ve Akademisyenler Derneği'nin organize ettiği I. Uluslararası Matematik, İstatistik ve Analitik Yöntemler Kongresi'nde bildiri olarak sunulmuştur.

b İletişim Yazarı: gulaydemir@cumhuriyet.edu.tr

c Dr. Öğr. Üyesi, Sivas Cumhuriyet Üniversitesi Sağlık Hizmetleri MYO ve ORCID ID: 0000-0002-3916-7639.

d Prof. Dr. Sivas Cumhuriyet Üniversitesi İktisadi ve İdari Bilimler Fakültesi İşletme Bölümü ve ORCID ID: 0000-0002-1868-1161

e Sivas Cumhuriyet Üniversitesi Sosyal Bilimler Enstitüsü ve ORCID ID: 0000-0001-8061-3322.
} 


\section{Giriş}

Hızla gelişen ve değişen iş dünyasında çalışanlar kendilerini güvende hissetmek ister. Bu nedenle çeşitli tasarruf yöntemleri ile geleceğe dönük yatırım yaparlar ya da emeklilik için ödemelerde bulunurlar. Yapılan ödemeler sonunda belli gün ya da prim tamamlandıktan sonra emeklilik hakkı kazanılır. Günümüzde hayat standartlarını daha iyi bir konuma getirmek ve emeklilik döneminde ek bir gelir sağlamak amacıyla bireysel emeklilik sistemi oluşturulmuştur. Bu sistemin üyesi olmak için bir emeklilik şirketiyle emeklilik sözleşmesi akdedilmesi yeterli olacaktır. Sistemde en az 10 yıl kalmak ve 56 yaşını tamamlamak da bireysel emekli olmanın şartlarıdır. Bireysel emeklilik şirketlerinin faaliyetlerini Hazine Müsteşarlığı, fonların ve portföy yöneticilerinin faaliyetlerini Sermaye Piyasası Kurulu denetlemektedir. Tüm bireysel emeklilik şirketleri yılda en az bir defa bağımsız diş denetime tabidir. Şirketlerin günlük faaliyetleri Emeklilik ve Gözetim Merkezi tarafından elektronik ortamda izlenmektedir. Sistemdeki her şirketin internet sitesinde katılımcıya ait şifre ile girilebilen güvenli sayfadan bireysel emeklilik bilgilerine erişilebilir. Bireysel emeklilik hesapları Takasbank nezdinde de tutulmaktadır.

Bireysel emeklilik sistemine ödenen katkı payı o yılın brüt asgari ücretinin \%25'i ile sınırlıdır ve devlet katkısı adı altında katılımcıların hesabına yatırılır. Bu katkı payları da varsa kesintilerden sonra ilgili emeklilik yatırım fonlarında değerlendirilir (Baştürk, Çakmak ve Demirtaş, 2017). Emeklilik yatırım fon varlıklarının toplam değerinin GSYH'ya oranı, emeklilik yatırım fonları için en temel göstergelerin başındadır. Ülkemizde 16 Mayıs 2000 yılında TBMM sunulan bir tasarı ile vatandaşların emekli olması için gönüllü olarak yatırdıkları tasarruflarını düzenleyen bir fon sisteminin kurulması amaçlanmıştır. Bu tasarı 7 Ekim 2001 yılında yürürlüğe girerek 27 Ekim 2003 de emeklilik ile ilgili şirketler faaliyetlerine başlamıştır. 14 Haziran 2007 tarihinde Sigortacılık Kanunu ile daha önceden kabul edilen kanun tasarısının bazı maddeleri değiştirilmiş ve yeni hükümler eklenmiştir. 1 Ocak 2013 de bireysel emeklilik ile ilgili yönetmelik kabul edilerek uygulamaya başlanmıştır. 10 Ağustos 2016 tarihinde işverenlerin çalışanlarını otomatik olarak emeklilik sistemine dahil etmesine ilişkin esaslar getirilmiştir. Uygulamaya 1 Ocak 2017 tarihinde geçilmiştir (Baştürk vd., 2017). Ülkemizde bireysel emeklilik; T.C. Başbakanlık Hazine Müsteşarlığı, Sermaye Piyasası Kurulu, İstanbul Takas ve Saklama Bankası A.Ş. (Takasbank), Emeklilik Şirketleri ve Emeklilik Gözetim Merkezi A.Ş. unsurlarından oluşmaktadır (Emeklilik Gözetim Merkezi, 2016). 31.12.2016 tarihi itibariyle sistemdeki katılımcı sayısı 6,6 milyon kişiye, akdedilen sözleşme sayısı da 7,8 milyon adede yaklaşmıştır (T.C. Başbakanlık Hazine Müsteşarlığı/ Sigortacılık ve Özel Emeklilik Raporları, 2016). 31.12.2019 tarihi itibariyle sisteme katılanlar bir önceki yıla göre \%0,52 artmıştır. Emeklilik yatırım fonu büyüklüğü de \%24,46 artmıştır. Sistemin katılımcıları ikamet ettikleri illere göre en çok Marmara Bölgesinde sonra İç Anadolu ve daha sonra da Ege Bölgesinde sisteme kayıtlı bulunmaktadır. 2019 yılı sonu itibariyle sistemdeki sözleşmelerin ortalama sistemde kalma süresi 4,2 yıldır. Sisteme dahil olan nüfusun yaş ortalaması 40,9 ve katılımcıların \%55'i erkek ve \%45'i kadındır (Bireysel Emeklilik Gelişim Raporu, 2019).Bireysel emeklilik sistemi, Gri İlişkisel Analiz ve bireysel emeklilik şirketlerinin performans ölçümü ile ilgili çalışmalar ayrı ayrı ele alınmış ve yapılan çalışma sayısının çok olmasından dolayı en güncel olanlara yer verilmiştir.

a. Bireysel Emeklilikle İlgili Çalışmalar

Bireysel emeklilikle ilgili çok sayıda çalışma yapılmıştır ve bunların bazıları aşağıdaki şekilde özetlenmiştir: 
Gülcan tarafından yapılan çalışmada (2017), BES hakkında farkındalık düzeylerini tespit etmek için öğrencilere uygulanan anket çalışması değerlendirilmiştir. Polat ve Kekeç tarafından yapılan çalışmada (2017), BES'in dünya ülkeleri ve Türkiye'deki işleyişine değinilmiş Türk vergi sistemi açısından BES analiz edilmiştir. Aydın ve Selçuk tarafından yapılan çalışmada (2017), kolayda örnekleme ile elde edilen veriler lojistik regresyon ile analiz edilmiş ve değişkenlerin anlamlılıkları test edilmiştir. Atılğan tarafından yapılan çalışmada (2018), Türkiye'deki bireysel emeklilik sisteminin istenen düzeye ulaşması için yapılacaklar üzerine bir değerlendirmeye yer verilmiştir. Kurin tarafından yapılan çalışmada (2018), bireysel emeklilik sistemi kavramından, tarihsel süreç içinde gelişimi ve Türkiye' de bireysel emeklilik sisteminin esasları, Türkiye'de bireysel emeklilik sistemini ilgilendiren kurum ve kuruluşlar, Türkiye'de bireysel emeklilik sisteminde idari suçlar ve cezaları bireysel emeklilik sisteminin avantajları ve dezavantajlarından bahsedilmiştir. Akpınar ve Demirci tarafından yapılan çalışmada (2018), bireysel emeklilik sistemine zorunlu giriş sonucunda sağlık sektörü çalışanlarının ücretlerinden yapılacak muhtemel kesinti tutarları ve kesintinin hangi hesapta muhasebeleştirileceği ile ilgili örnekler verilmiştir. Şataf ve Yıldırım tarafından yapılan çalışmada (2019), Ordu ilinde rastgele seçilen işgücüne dahil olan 371 kişiye 30 soruluk anket uygulanarak BES'nin tanınırlığı ve bireylerin sisteme yönelik düşüncelerinin tespit edilmesi için frekans ve yüzde analizi yapılmıştır. Can ve Eyidiker tarafından yapılan çalışmada (2019), otomatik katılım sisteminin yaklaşık üç yıl içerisindeki gelişimini incelenerek Emeklilik Gözetim Merkezi'nden elde edilen veriler yardımıyla değerlendirmeler yapılmıştır. Yumurtacı ve Onursal tarafından yapılan çalışmada (2019), bireysel emeklilik sistemine talebi etkileyen ve ayrılma süreçlerine neden olan sınırlandırıcı unsurların, kısıtların, düşünce süreçleri ile bulunması ve bu kısıtların ortadan kaldırılmasına yönelik çözüm önerileri ortaya konulmuştur.

b. Gri İlişkisel Analiz ile İlgili Çalışmalar

Gri İlişkisel Analiz ile ilgili çok sayıda çalışma yapılmıştır ve bunların bazıları aşağıdaki şekilde özetlenmiştir:

Orakçı ve Özdemir tarafından yapılan çalışmada (2017), İnsani Gelişmişlik Endeksi kullanılarak GİA ve MOORA yöntemleri ile ülkelerin sıralaması yapılmıştır. Çakır tarafından yapılan çalışmada (2017), kriterler SWARA ile ağırlıklandırılmış ve alternatifler GİA ile değerlendirilmiştir. Bilge, Motorcu ve Ivanov tarafından yapılan çalışmada (2017), proses parametrelerinin optimizasyonu GİA ile yapılmış ve regresyon analizi ile bir denklem tahmin edilmiştir. Uğur ve Baykan tarafından yapılan çalışmada (2017), 6 farklı kriter ve 9 farklı alternatif arasından en uygun konutun satın alınmasına dayalı bir uygulama yapılmıştır. Güleç ve Özkan tarafından yapılan çalışmada (2018), 2005-2016 yıllan arasında Borsa İstanbul'da faaliyet gösteren 16 çimento şirketinin finansal performansları Gri İlişkisel Analiz ile incelenmiştir. Başdeğirmen ve Işıldak tarafından yapılan çalışmada (2018), ulaştırma sektöründe faaliyet gösteren sekiz işletmenin finansal performansı Gri İlişkisel Analiz yöntemi ile değerlendirilmiştir. Tezergil tarafından yapılan çalışmada (2018), 2014-2016 yılları arasında Türkiye'deki 50 portföy yönetim şirketlerine ait gelir gider tablolarından elde edilen üretimle ilgili değişkenler kullanılarak performans sıralamaları Gri İlişkisel Analiz ile yapılmış ve sonuçlar yorumlanmıştır. Baş tarafından yapılan çalışmada (2019), 2018 yılında meydana gelen kur dalgalanmalarının Borsa İstanbul (BİST)'de işlem gören çimento işletmelerinin 20172018 yıllarındaki finansal yapıları ile bu yıllara ait kapanış ve hacimlerinde meydana gelen değişimin finansal performanslarındaki etkileri gri ilişkisel analiz tekniği ile belirlenmiş ve yorumlanmıştır. 
Akgül tarafından yapılan çalışmada (2019), borsa İstanbul'da faaliyet gösteren sigorta şirketlerinin toplam prim üretimi, ödenmiş zararlar, primler / özkaynaklar, özkaynaklar / teknik karşılıklar, elde tutma oranı, zarar oranı (net), vergi / prim alınmadan önceki kar, net kar veya zarar / özkaynaklar gibi finansal oranlarına göre performans analizi yapılmıştır. Ayrica, 2018-Q1, 2018-Q2, 2018-Q3 ve 2018-Q4 dönemlerine ait oranlar kullanılarak performansı en iyi ve en kötü şirket belirlenmiştir. Kaygın, Bağcı ve Tanır tarafından yapılan çalışmada (2019), BİST KOBİ Sanayi Endeksinde faaliyet gösteren şirketlerin finansal tablolarından elde edilen bilgiler kullanılarak 10 adet finansal oranının ağırlıkları ortalama ağırlık yöntemi ile belirlenmiş ve 27 işletmenin finansal performansları Gri İlişkisel Analiz (GİA) yöntemi ile tespit edilmeye çalışılmıştır.

c. Bireysel Emeklilik Şirketlerinin Performans Ölçümü ile İlgili Çalışmalar

Bireysel emeklilik şirketlerinin performans ölçümü ile ilgili çok sayıda çalışma yapılmıştır ve bunların bazıları aşağıdaki şekilde özetlenmiştir:

Çömlekçi ve Gökmen tarafından yapılan çalışmada (2017), BES katılımını etkileyen faktörler belirlenerek katılımcıların demografik özelliklerine göre veriler Faktör Analizi ile değerlendirilmiştir. Kırkağaç ve Dalkılıç tarafından yapılan çalışmada (2017), 2012-2016 arasında Türkiye'deki 15 tane emeklilik şirketinin finansal performansları Temel Bileşenler Analizi ve Kümeleme Analizi teknikleri ile ölçülmüştür. Bülbül ve Baykal tarafından yapılan çalışmada (2017), 2012-2016 yılları arasında hayat dışı sigorta şirketlerinin mali ve mali olmayan girdi/çıktıları kullanılarak performanslarının sıralaması VIKOR yöntemi ile yapılmıştır. Köse ve Türel tarafından yapılan çalışmada (2017), 2014-2016 yılları arasında faaliyet gösteren 26 sigorta şirketinin beş kriter ile GİA kullanılarak analizi yapılmıştır. Gürol ve Hazar tarafından yapılan çalışmada (2017), 2010-2016 yılsonu finansal tablolardan elde edilen verilerle sigorta şirketlerinin CAMELS Yöntemi etkinlik analizi yapılmıştır. Çetiner ve Gündoğdu tarafından yapılan çalışmada (2018), emeklilik yatırım fonlarının 2011-2017 döneminde gösterdikleri gelişme çeşitli kriterlerle değerlendirilmiştir. İskenderoğlu, Arslan ve Çelik tarafından yapılan çalışmada (2019), bireysel emeklilik sisteminde yer alan fonların performanslarının Sharpe Oranı, Treynor Oranı ve Jensen Ölçütü ile değerlendirmeleri yapılmıştır. Gezen ve Kalmış tarafından yapılan çalışmada (2019), 8 farklı türdeki bireysel emeklilik yatırım fonları 04.01.2010-31.12.2018 dönemleri kullanılarak Aşağ1 Yönlü Risk, Sharpe Oranı ve Sortino Oranı ölçüleri ile değerlendirilmiştir.

Bu çalışmada 24.11.2017 tarihli Emeklilik ve Gözetim Merkezinin internet sayfasında yer alan 18 tane bireysel emeklilik şirketinin performansının ölçümü amaçlanmaktadır. Söz konusu işletmelerin performans ölçümü Gri İlişkisel Analiz ile yapılacaktır. İzleyen başlıkta veriler ve analizin yöntemi olan Gri İlişkisel Analiz açıklanacaktır. Son olarak analiz sonucunda elde edilen bulgular ortaya konulacak ve çalışmanın sonuçlarına yer verilecektir.

\section{Yöntem}

Çalışmadaki veriler, 24.11.2017 tarihli Emeklilik ve Gözetim Merkezi'nin internet sayfasında yer alan 18 şirketin bireysel emeklilik temel göstergelerinden oluşmaktadır. Tablo 1'de alternatifleri oluşturan şirketler ve onlara ait analizde kullanılan kodlar parantez içinde yazılmıştır. Katılımcı sayısı, katılımcıların fon tutarı, devlet katkısı fon tutarı, katkı payı tutarı, emekli olan katılımcı sayısı çalışmanın kriterlerini oluşturmakta olup onlara ait kodlarda parantez içinde yazılmıştır. Çalışmanın verileri 24.11.2017 tarihli veriler ve belirtilen 18 bireysel emeklilik şirketi ve katılımcı sayısı, katılımcıların fon tutarı, devlet katkısı fon tutarı, 
katkı payı tutarı, emekli olan katılımcı sayısı kriterleri ile sınırlıdır. Aegon Emeklilik ve Hayat $\left(\mathrm{A}_{1}\right)$, Allianz Hayat ve Emeklilik $\left(\mathrm{A}_{2}\right)$, Allianz Yaşam ve Emeklilik $\left(\mathrm{A}_{3}\right)$, Anadolu Hayat ve Emeklilik ( $\left.\mathrm{A}_{4}\right)$, Avivasa Emeklilik ve Hayat ( $\left.\mathrm{A}_{5}\right)$, Axa Hayat ve Emeklilik ( $\left.\mathrm{A}_{6}\right)$, Bereket Emeklilik ve Hayat (A7), BNP Paribas Cardif Emeklilik (A8), Cigna Finans Emeklilik ve Hayat $\left(\mathrm{A}_{9}\right)$, Fiba Emeklilik ve Hayat (A10), Garanti Emeklilik ve Hayat (A11), Groupama Emeklilik $\left(\mathrm{A}_{12}\right)$, Halk Hayat ve Emeklilik ( $\left.\mathrm{A}_{13}\right)$, Katılım Emeklilik ve Hayat ( $\left.\mathrm{A}_{14}\right)$, Metlife Emeklilik ve Hayat (A15), NN Hayat ve Emeklilik (A16), Vakıf Emeklilik ve Hayat (A17), Ziraat Hayat ve Emeklilik (A18) ve Katılımcı Sayısı (K1), Katılımcıların Fon Tutar1/TL (K2), Devlet Katkısı Fon Tutarı/ TL (K $\left.\mathrm{K}_{3}\right)$, Katkı Payı Tutarı/ TL (K4), Emekli Olan Katılımcı Sayısı (K5) şeklinde Tablo 1 'de verilmiştir.

Tablo 1. Bireysel Emeklilik Sistemindeki Şirketler

\begin{tabular}{|c|c|c|c|c|c|}
\hline Alternatifler & $\mathbf{K}_{1}$ & $\mathbf{K}_{2}$ & $\mathbf{K}_{3}$ & $\mathbf{K}_{4}$ & $\mathbf{K}_{5}$ \\
\hline $\mathrm{A}_{1}$ & 41.213 & 143.010.406 & 15.350 .220 & 104.336 .853 & 412 \\
\hline $\mathrm{A}_{2}$ & 110.070 & 2.174.479.304 & 275.178 .903 & 1.617 .718 .725 & 2.896 \\
\hline $\mathrm{A}_{3}$ & 774.975 & 9.038 .411 .521 & 1.003.547.996 & 6.708 .130 .243 & 7.813 \\
\hline $\mathrm{A}_{4}$ & 1.141 .926 & 12.109 .073 .144 & 1.863 .831 .543 & 9.444 .854 .138 & 15.506 \\
\hline $\mathrm{A}_{5}$ & 884.996 & 12.853 .395 .262 & 1.696 .166 .645 & 10.021.200.257 & 12.464 \\
\hline $\mathrm{A}_{6}$ & 34.927 & 290.585 .821 & 56.708 .720 & 244.427 .167 & 39 \\
\hline A 7 & 111.604 & 318.723 .837 & 67.610 .027 & 254.695 .753 & 21 \\
\hline A 8 & 182.911 & 1.781.701.627 & 247.350 .589 & 1.424 .000 .599 & 1.698 \\
\hline A9 & 108.132 & 638.076 .701 & 118.102 .477 & 530.500 .638 & 86 \\
\hline $\mathrm{A}_{10}$ & 42.219 & 437.006 .366 & 53.605 .744 & 381.069 .142 & 148 \\
\hline $\mathrm{A}_{11}$ & 1.196 .327 & 9.907 .618 .536 & 1.463 .315 .692 & 7.782 .523 .555 & 8.379 \\
\hline $\mathrm{A}_{12}$ & 56.886 & 856.293 .344 & 92.790 .251 & 615.012 .719 & 2.711 \\
\hline $\mathrm{A}_{13}$ & 494.433 & 2.585 .865 .286 & 470.443 .649 & 2.260 .754 .162 & 200 \\
\hline $\mathrm{A}_{14}$ & 191.517 & 784.986 .735 & 155.286 .310 & 714.223 .767 & 41 \\
\hline $\mathrm{A}_{15}$ & 188.541 & 1.263 .556 .056 & 211.711.396 & 1.074 .546 .329 & 264 \\
\hline $\mathrm{A}_{16}$ & 266.995 & 2.442 .509 .826 & 346.048 .041 & 1.887 .812 .605 & 3.355 \\
\hline $\mathrm{A}_{17}$ & 486.278 & 5.047 .101 .425 & 687.404 .173 & 3.985 .896 .303 & 5.383 \\
\hline $\mathrm{A}_{18}$ & 572.589 & 2.765.487.747 & 518.518 .638 & 2.383.686.402 & 761 \\
\hline
\end{tabular}

Kaynak: Emeklilik Gözetim Merkezi, BES Temel Göstergeleri, 2017 


\section{Araştırma Modeli}

Gri İlişkisel Analiz' in tüm alanlarda rahatlıkla kullanılması ve az veri ile bile çok iyi sonuçlar vermesi nedenleri çalışmanın uygulama kısmı için tercih edilen yöntem olmasını sağlamıştır. 1982 yılında Deng Ju Long "Gri Sistemler ve Kontrol Problemleri” isimli çalışmasında ilk kez Gri Sistem Teorisi (GST)' den bahsetmiştir. GST, belirsiz durumların sayısal hale getirilmesidir. GST ile bulanık mantık karşılaştıııldığında, GST daha basit ve daha anlaşılır bir modeldir (Aydemir, Fevzi ve Özdemir, 2013). Gri Teori; sayılabilir, kesikli sayısal ve nitelikli seriler arasındaki ilişkinin analizinde kullanılır (Sofyalığlu, 2011). GST 4 farklı alt gruba ayrılmıştır (Büyükgebiz, 2013). Gri İlişkisel Analiz, Gri Modelleme, Gri Tahmin ve Gri Karar Verme şeklindedir. GST'nin disiplinler arası karşılaştırılması Tablo 2' de verilmiştir.

Tablo 2. GST’nin Karşılaştırılması

\begin{tabular}{lccc}
\hline & İstatistik & Bulanık Teori & Gri Teori \\
\hline $\begin{array}{l}\text { Temel Kavramlar } \\
\text { Matematiksel } \\
\text { Yöntemler }\end{array}$ & $\begin{array}{c}\text { Sinırsız veri, rassallık } \\
\text { ilkeleri }\end{array}$ & Eksik tanımlama & $\begin{array}{c}\text { Yetersiz sayıda veri ve çok } \\
\text { belirgin olmama }\end{array}$ \\
$\begin{array}{l}\text { Matematiksel } \\
\text { İşlemler }\end{array}$ & Cantor Kümesi & Bulanık küme & Hazy Kümesi \\
Veri Sayıları & İstatistik & Bulanık çıkarım & Oluşum ve ilişkiler \\
Veri Dağılımı & Çok sayıda & Deneyimlere göre & En az 4 tane \\
& Kendine özgü bir & Üyelik & Herhangi bir veri dağılımı \\
& dağılım şekli & fonksiyonuna bağlı & yok
\end{tabular}

Kaynak: Baş ve Çakmak, 2010, s.63-82

GST, küçük örneklemlerde ve dağılımın şeklini bilmeden, belirsiz durumlarda bile kolaylıkla uygulanabilir (Liu ve Lin, 2006). GST'de bilginin netliğini göstermek için renkler kullanılmıştır. Gri; bilginin tam olarak bilinmediği, beyaz; bilginin tam olduğu, siyah; bilginin olmadığı anlamına gelir. GST'de siyah durumundaki bilgiyi gri duruma getirmek hedeflenmektedir (Liu vd. 2006). Renkli sistemler arasındaki karşılaştırma Tablo 3'te özetlenmiştir.

Tablo 3. Siyah, Beyaz ve Gri Sistemler Arasına Karşılaştırma

\begin{tabular}{lccc}
\hline & Siyah & Gri & Beyaz \\
\hline Bilgi & Bilinmeyen & Eksik & Bilinen \\
Görünüş & Koyu & Gri & Parlak \\
Süreç & Yeni & Eksik yerine yeni & Eski \\
Özellik & Kaos & Karmakarışıklı & Düzen \\
Yöntem & Negatif & Dönüşüm & Pozitif \\
Tutum & Müsamahalı & Tolerans tayini & Net \\
Karar (Sonuç) & Sonuç yok & Çeşitli sonuçlar & Yegâne sonuç \\
\hline
\end{tabular}

Kaynak: Liu ve Lin, 2006, s.5-15 
GİA sıralama ve sınıflama şeklinde karar verme yöntemidir. Kesikli veri gruplarında, eksik bilginin bulunduğu problemlerde tercih edilir (Sofyalığlu, 2011). GİA bazı avantajları vardır. Bunlar: (Ayrıçay, Özçalı ve Kaya, 2013; Bektaş ve Tuna, 2013).

- Veri sayısı az olabilir

- Veriler belirsiz olabilir

- Gri ilişki katsayılarının hesaplanması kolay

- Veri setinin dağılım şeklinin bilinmesine ihtiyacın olmaması

- Hesaplaması kolay ve belirli işlem adımlarının olmasıdır.

\section{Evren ve Örneklem}

Emeklilik ve Gözetim Merkezi'nin internet sayfasında yer alan 18 şirketin bireysel emeklilik temel göstergeleri çalışmanın örneklemini oluşmaktadır.

\section{Veri Toplama Araçları}

Çalışmada kullanılan veri toplama aracı olarak doküman inceleme yöntemi tercih edilmiştir. Bu yöntemle veriler Emeklilik ve Gözetim Merkezi'nin internet sayfasından alınmıştır.

\section{Verilerin Toplanması ve Analizi}

Veriler 24.11.2017 tarihli Emeklilik ve Gözetim Merkezi'nin internet sayfasından alınarak GİA yönteminin işlem adımlarına tabii tutulmuştur. GİA, belirli aşamalardan oluşan bir süreçler bütünüdür. Aşağıda açıklandığı şekilde 6 adımdan oluşur (Wu, 2002; Zhai, Khoo ve Zhang, 2009; Athawale ve Chakraborty, 2011):

Adım 1: Karar matrisinin oluşturulması

Satırların (m) alternatifleri, sütunların $(n)$ kriterleri ifade ettiği $\boldsymbol{x}_{\boldsymbol{i}}(\boldsymbol{j})$ elemanlarından oluşan $\boldsymbol{n} \boldsymbol{x} \boldsymbol{m}^{\prime}$ lik karar matrisinin oluşturulmasıdır. $\boldsymbol{x}_{\boldsymbol{i}}(\boldsymbol{j}): i$. alternatifin $j$. kriterdeki değeri Eşitlik (1)'deki gibi elde edilir.

$\mathrm{X}=\left[\begin{array}{ccc}x_{1}(1) & x_{1}(2) \ldots & x_{1}(\mathrm{~m}) \\ x_{2}(1) & x_{2}(2) \ldots & x_{2}(\mathrm{~m}) \\ \vdots & \vdots & \vdots \\ x_{\mathrm{n}}(1) & x_{\mathrm{n}}(2) \ldots & x_{\mathrm{n}}(\mathrm{m})\end{array}\right]$

$\mathrm{i}=1,2, \ldots, \mathrm{n}$ ve $\mathrm{j}=1,2, \ldots, \mathrm{m}$

Adım 2: Referans serisi ve karşılaş̧ırma matrisinin belirlenmesi

Referans serisi, $\mathrm{x}_{0}=\left(\mathrm{x}_{0}(\mathrm{j})\right)$

$\boldsymbol{j}=\mathbf{1}, \mathbf{2}, \ldots, \boldsymbol{n}$ şeklinde gösterilir.

$\boldsymbol{x}_{\mathbf{0}}(\boldsymbol{j}): \boldsymbol{j}$. normalize edilen kriterin en büyük olanı karar matrisinin ilk satırına referans serisi ilave edilir ve böylece karşılaştırma matrisi oluşturulmuş olur.

Adım 3: Karar matrisinin normalize edilmesi

Gri ilişki katsayılarının hesaplanmasında göstergeler arasında farklı ölçüt kullanılmasından dolayı verilerin standart hale dönüştürülmesi gerekir. Bu dönüştürme işlemine normalizasyon 
denir. Normalizasyon işlemleri fayda, maliyet veya en uygun (optimal) durumuna göre farklı şekillerde yapılır (Tsai, Chang ve Chan, 2003; Yıldırım ve Önder, 2015).

Fayda durumu: Matristeki değerlerin büyük olması amaca olumlu katkı sağlıyorsa kullanılır ve Eşitlik (2)'deki gibi elde edilir.

$x_{i}^{*}=\frac{x_{i}(j)-\min _{j} x_{i}(j)}{\max _{j} x_{i}(j)-\min _{j} x_{i}(j)}$

Maliyet durumu: Matristeki değerlerin küçük olması amaca olumlu katkı sağlıyorsa kullanılır ve Eşitlik (3)'deki gibi elde edilir.

$x_{i}^{*}=\frac{\max _{j} x_{i}(j)-x_{i}(j)}{\max _{j} x_{i}(j)-\min _{j} x_{i}(j)}$

Optimal durumu: Matristeki değerlerin belirlenen bir optimal değere göre amaca olumlu katkı sağlıyorsa kullanılır ve Eşitlik (4)'deki gibi elde edilir.

$x_{i}^{*}=\frac{\left|x_{i}(j)-x_{0 b}(j)\right|}{\max _{j} x_{i}(j)-x_{0 b}(j)}$

$\boldsymbol{x}_{\mathbf{0} \boldsymbol{b}}(\boldsymbol{j}): \boldsymbol{j}$. kriterin hedef değeri olup belirlenen optimal değerdir ve

$\max _{\boldsymbol{j}} \boldsymbol{x}_{\boldsymbol{i}}(\boldsymbol{j}) \geq \boldsymbol{x}_{\mathbf{0} b}(\boldsymbol{j}) \geq \boldsymbol{m i n}_{\boldsymbol{j}} \boldsymbol{x}_{\boldsymbol{i}}(\boldsymbol{j})$ aralığında yer almaktadır.

$\mathrm{Bu}$ işlemlerden sonra karar matrisi normalize edilmiş olur ve yeni bir $\boldsymbol{X}^{*}$ matrisi elde edilir ve Eşitlik (5)'deki gibi elde edilir.

$\mathrm{X}^{*}=\left[\begin{array}{cccc}x_{1}^{*}(1) & x_{1}^{*}(2) \ldots & x_{1}^{*}(\mathrm{n}) \\ x_{2}^{*}(1) & x_{2}^{*}(2) \ldots & x_{2}^{*}(\mathrm{n}) \\ \vdots & \vdots & \vdots \\ x_{\mathrm{m}}^{*}(1) & x_{\mathrm{m}}^{*}(2) \ldots & x_{\mathrm{m}}^{*}(\mathrm{n})\end{array}\right]$

Adım 4: Mutlak değer matrisinin hesaplanması

$\boldsymbol{x}_{\mathbf{0}}$ ile $\boldsymbol{x}_{\boldsymbol{i}}^{*}$ arasındaki farkın mutlak değeri $\Delta_{\mathbf{0} \boldsymbol{i}}(\boldsymbol{j})$ olarak gösterilir ve Eşitlik (6)'daki gibi elde edilir ve Eşitlik (7)'deki gibi elde edilir.

$\Delta_{0 i}(j)=\left|x_{0}(j)-x_{i}^{*}(j)\right| i=1,2, \ldots, m$ ve $j=1,2, \ldots, n$

$\Delta_{0 \mathrm{i}}=\left|\begin{array}{cccc}\Delta_{01}(1) & \Delta_{01}(2) \ldots & \Delta_{01}(\mathrm{n}) \\ \Delta_{02}(1) & \Delta_{02}(2) & \ldots & \Delta_{02}(\mathrm{n}) \\ \vdots & \vdots & & \vdots \\ \Delta_{0 \mathrm{~m}}(1) & \Delta_{0 \mathrm{~m}}(2) & \ldots & \Delta_{0 \mathrm{~m}}(\mathrm{n})\end{array}\right|$

Adım 5: Gri ilişkisel katsayı matrisinin belirlenmesi

Eşitlik (8)'deki gibi elde edilir.

$\gamma_{0 i}(j)=\frac{\Delta_{\min }+\zeta \Delta_{\max }}{\Delta_{0 i}(j)+\zeta \Delta_{\max }}$

$\Delta_{\max }: \max _{i} \max _{j} \Delta_{0 i}(j)$ şeklinde bulunur ve her dizi içerisindeki en büyük değer değişimidir.

$\Delta_{\min }=\min _{i} \min _{j} \Delta_{0 i}(j)$ şeklinde bulunur ve her dizi içerisindeki en küçük değer değişimidir.

$\boldsymbol{\Delta}_{\mathbf{0} i}(\boldsymbol{j}): \boldsymbol{\Delta}_{\boldsymbol{i}}$ fark veri dizisindeki j. değeri gösterir.

$\zeta$ : ayırıcı katsayı olup $[\mathbf{0}, \mathbf{1}]$ aralığındadır.

Literatürde ayırıı katsayının genellikle 0,5 olarak alındığı görülmektedir (Özdemir ve Deste, 2009; Uçkun ve Girginer, 2011). 
Adım 6: Gri ilişkisel derecelerin hesaplanması

$\left(\boldsymbol{x}_{\boldsymbol{i}}^{*}\right)$ ile $\left(\boldsymbol{x}_{\mathbf{0}}^{*}\right)$ arasındaki geometrik benzerliğin ölçüsüne gri ilişki derecesi denir. Bu derece 1 ise, karşılaştııılan iki matris birbirinin aynısıdır. Gri ilişki derecesi belirlenirken, kriter ağırlıkları eşit ya da farklı olması durumu ile farklılık gösterir. Ağırlıklandırmanın eşit olduğu durumda gri ilişki derecesi Eşitlik (9)'daki gibi elde edilir.

$\Gamma_{0 i}=\frac{1}{n} \sum_{j=1}^{n} \gamma_{0 i}(j)$ ve $i=1,2, \ldots, m$

(9)

şeklinde hesaplanır. Ağırlıklandırmanın farklı olduğu durumda gri ilişki derecesi Eşitlik (10)'daki gibi elde edilir.

$\Gamma_{0 \mathrm{i}}=\sum_{\mathrm{j}=1}^{\mathrm{n}}\left[\mathrm{w}_{\mathrm{i}}(\mathrm{j}) \cdot \gamma_{0 \mathrm{i}}(\mathrm{j})\right]$ ve $i=1,2, \ldots, m$

$\boldsymbol{w}_{\boldsymbol{i}}:$ i. ölçütün önem derecesi

Kriterlerin ağırlıklandırılmasında AHS, DEMATEL, ENTROPY gibi yöntemler kullanılabilir. Gri ilişki derecesi hesaplanmasından sonra büyükten küçüğe doğru sıralama yapılır. İlk sırada yer alan seçenek en uygun veya en iyi alternatif olur.

\section{Bulgular}

GİA adımları uygulanarak analiz işlemi tamamlanmıştır.

Adım 1: Karar matrisinin oluşturulması $(X)$

$\begin{array}{|rrrrr|}41.213 & 143.010 .406 & 15.350 .220 & 104.336 .853 & 412 \\ 110.070 & 2.174 .479 .304 & 275.178 .903 & 1.617 .718 .725 & 2.896 \\ 774.975 & 9.038 .411 .521 & 1.003 .547 .996 & 6.708 .130 .243 & 7.813 \\ 1.141 .926 & 12.109 .073 .144 & 1.863 .831 .543 & 9.444 .854 .138 & 15.506 \\ 884.996 & 12.853 .395 .262 & 1.696 .166 .645 & 10.021 .200 .257 & 12.464 \\ 34.927 & 290.585 .821 & 56.708 .720 & 244.427 .167 & 39 \\ 111.604 & 318.723 .837 & 67.610 .027 & 254.695 .753 & 21 \\ 182.911 & 1.781 .701 .627 & 247.350 .589 & 1.424 .000 .599 & 1.698 \\ 108.132 & 638.076 .701 & 118.102 .477 & 530.500 .638 & 86 \\ 42.219 & 437.006 .366 & 53.605 .744 & 381.069 .142 & 148 \\ 1.196 .327 & 9.907 .618 .536 & 1.463 .315 .692 & 7.782 .523 .555 & 8.379 \\ 56.886 & 856.293 .344 & 92.790 .251 & 615.012 .719 & 2.711 \\ 494.433 & 2.585 .865 .286 & 470.443 .649 & 2.260 .754 .162 & 200 \\ 191.517 & 784.986 .735 & 155.286 .310 & 714.223 .767 & 41 \\ 188.541 & 1.263 .556 .056 & 211.711 .396 & 1.074 .546 .329 & 264 \\ 266.995 & 2.442 .509 .826 & 346.048 .041 & 1.887 .812 .605 & 3.355 \\ 486.278 & 5.047 .101 .425 & 687.404 .173 & 3.985 .896 .303 & 5.383 \\ 572.589 & 2.765 .487 .747 & 518.518 .638 & 2.383 .686 .402 & 761\end{array}$

şeklinde $(X)$ karar matrisi oluşturulmuştur.

Adım 2: Referans serisi ve karşılaştırma matrisinin belirlenmesi

Referans serisi, seçeneklerin ölçütlerine göre aldığı en iyi değerleri alması yoluyla belirlenmiştir. Belirlenen referans serisi;

$X_{0}=\{1.196 .327,12.853 .395 .262,1.863 .831 .543,10.021 .200 .257,15.506\}$

Referans serisinin (RS) karar matrisine eklenmesi Tablo 4'te gösterilmiştir. 
Tablo 4. Referans Serisinin Karar Matrisine Eklenmesi

\begin{tabular}{lccccc}
\hline & $\mathbf{K}_{1}$ & $\mathbf{K}_{2}$ & $\mathbf{K}_{3}$ & $\mathbf{K}_{4}$ & $\mathbf{K}_{5}$ \\
\hline $\mathbf{R S}$ & 1.196 .327 & 12.853 .395 .262 & 1.863 .831 .543 & 10.021 .200 .257 & 15.506 \\
$\mathbf{A}_{1}$ & 41.213 & 143.010 .406 & 15.350 .220 & 104.336 .853 & 412 \\
$\mathbf{A}_{2}$ & 110.070 & 2.174 .479 .304 & 275.178 .903 & 1.617 .718 .725 & 2.896 \\
$\mathbf{A}_{3}$ & 774.975 & 9.038 .411 .521 & 1.003 .547 .996 & 6.708 .130 .243 & 7.813 \\
$\mathbf{A}_{4}$ & 1.141 .926 & 12.109 .073 .144 & 1.863 .831 .543 & 9.444 .854 .138 & 15.506 \\
$\mathbf{A}_{5}$ & 884.996 & 12.853 .395 .262 & 1.696 .166 .645 & 10.021 .200 .257 & 12.464 \\
$\mathbf{A}_{6}$ & 34.927 & 290.585 .821 & 56.708 .720 & 244.427 .167 & 39 \\
$\mathbf{A}_{7}$ & 111.604 & 318.723 .837 & 67.610 .027 & 254.695 .753 & 21 \\
$\mathbf{A}_{8}$ & 182.911 & 1.781 .701 .627 & 247.350 .589 & 1.424 .000 .599 & 1.698 \\
$\mathbf{A}_{9}$ & 108.132 & 638.076 .701 & 118.102 .477 & 530.500 .638 & 86 \\
$\mathbf{A}_{10}$ & 42.219 & 437.006 .366 & 53.605 .744 & 381.069 .142 & 148 \\
$\mathbf{A}_{11}$ & 1.196 .327 & 9.907 .618 .536 & 1.463 .315 .692 & 7.782 .523 .555 & 8.379 \\
$\mathbf{A}_{12}$ & 56.886 & 856.293 .344 & 92.790 .251 & 615.012 .719 & 2.711 \\
$\mathbf{A}_{13}$ & 494.433 & 2.585 .865 .286 & 470.443 .649 & 2.260 .754 .162 & 200 \\
$\mathbf{A}_{14}$ & 191.517 & 784.986 .735 & 155.286 .310 & 714.223 .767 & 41 \\
$\mathbf{A}_{15}$ & 188.541 & 1.263 .556 .056 & 211.711 .396 & 1.074 .546 .329 & 264 \\
$\mathbf{A}_{16}$ & 266.995 & 2.442 .509 .826 & 346.048 .041 & 1.887 .812 .605 & 3.355 \\
$\mathbf{A}_{17}$ & 486.278 & 5.047 .101 .425 & 687.404 .173 & 3.985 .896 .303 & 5.383 \\
$\mathbf{A}_{18}$ & 572.589 & 2.765 .487 .747 & 518.518 .638 & 2.383 .686 .402 & 761 \\
\hline & & & & & \\
\hline
\end{tabular}

Adım 3: Karar matrisinin normalize edilmesi

Veriler için fayda durumunda kullanılan normalizasyon işlemi uygulandı. Elde edilen sayılar $[0,1]$ aralığında yer alarak normalizasyon işlemi tamamlandı. Katılımcı sayısı kriteri için verilerin normalize edilmesi ile ilgili işlem adımı;

$x_{1}^{*}(1)=(41.213-34.927) /(1.196 .327-34.927)=0.005$

şeklindeki hesaplama ile tüm alternatiflerin kriterlerine ait normalize işlemleri yapılabilir. Aşağıda normalizasyon matrisi $\left(X^{*}\right)$ verilmiştir. 


$X^{*}=\left[\begin{array}{lllll}1.000 & 1.000 & 1.000 & 1.000 & 1.000 \\ 0.005 & 0,000 & 0,000 & 0,000 & 0,025 \\ 0,065 & 0,159 & 0,141 & 0,153 & 0,187 \\ 0,637 & 0,699 & 0,535 & 0,666 & 0,503 \\ 0,953 & 0,941 & 1,000 & 0,942 & 1,000 \\ 0,732 & 1,000 & 0,909 & 1,000 & 0,804 \\ 0,000 & 0,012 & 0,022 & 0,014 & 0,001 \\ 0,066 & 0,014 & 0,028 & 0,015 & 0,000 \\ 0,127 & 0,129 & 0,126 & 0,133 & 0,108 \\ 0,063 & 0,039 & 0,056 & 0,043 & 0,004 \\ 0,006 & 0,023 & 0,021 & 0,028 & 0,008 \\ 1,000 & 0,768 & 0,783 & 0,774 & 0,539 \\ 0,019 & 0,056 & 0,042 & 0,051 & 0,174 \\ 0,395 & 0,192 & 0,246 & 0,217 & 0,012 \\ 0,135 & 0,051 & 0,076 & 0,061 & 0,001 \\ 0,132 & 0,088 & 0,106 & 0,098 & 0,016 \\ 0,199 & 0,181 & 0,178 & 0,179 & 0,215 \\ 0,389 & 0,386 & 0,364 & 0,391 & 0,346 \\ 0,463 & 0,206 & 0,272 & 0,229 & 0,048\end{array}\right]$

Adım 4: Mutlak değer matrisinin oluşturulması

Referans serisi ile sıra değerleri arasındaki farkları alınır. Elde edilen mutlak değer matrisi Tablo 5'te verilmiştir.

Tablo 5. Mutlak Değer Tablosu

\begin{tabular}{lccccc}
\hline & $\mathbf{K}_{1}$ & $\mathbf{K}_{2}$ & $\mathbf{K}_{3}$ & $\mathbf{K}_{4}$ & $\mathbf{K}_{5}$ \\
\hline $\mathbf{R S}$ & 1.000 & 1.000 & 1.000 & 1.000 & 1.000 \\
$\mathbf{A}_{1}$ & 0.995 & 1.000 & 1.000 & 1.000 & 0.975 \\
$\mathbf{A}_{2}$ & 0.935 & 0.841 & 0.859 & 0.847 & 0.813 \\
$\mathbf{A}_{3}$ & 0.363 & 0.301 & 0.465 & 0.334 & 0.497 \\
$\mathbf{A}_{4}$ & 0.047 & 0.059 & 0.000 & 0.058 & 0.000 \\
$\mathbf{A}_{5}$ & 0.268 & 0.000 & 0.091 & 0.000 & 0.196 \\
$\mathbf{A}_{6}$ & 1.000 & 0.988 & 0.978 & 0.986 & 0.999 \\
$\mathbf{A}_{7}$ & 0.934 & 0.986 & 0.972 & 0.985 & 1.000 \\
$\mathbf{A}_{8}$ & 0.873 & 0.871 & 0.874 & 0.867 & 0.892 \\
$\mathbf{A}_{9}$ & 0.937 & 0.961 & 0.944 & 0.957 & 0.996 \\
$\mathbf{A}_{10}$ & 0.994 & 0.977 & 0.979 & 0.972 & 0.992 \\
$\mathbf{A}_{11}$ & 0.000 & 0.232 & 0.217 & 0.226 & 0.461 \\
$\mathbf{A}_{12}$ & 0.981 & 0.944 & 0.958 & 0.949 & 0.826 \\
$\mathbf{A}_{13}$ & 0.605 & 0.808 & 0.754 & 0.783 & 0.988 \\
$\mathbf{A}_{14}$ & 0.865 & 0.949 & 0.924 & 0.939 & 0.999 \\
$\mathbf{A}_{15}$ & 0.868 & 0.912 & 0.894 & 0.902 & 0.984 \\
$\mathbf{A}_{16}$ & 0.801 & 0.819 & 0.822 & 0.821 & 0.785 \\
$\mathbf{A}_{17}$ & 0.611 & 0.614 & 0.636 & 0.609 & 0.654 \\
$\mathbf{A}_{18}$ & 0.537 & 0.794 & 0.728 & 0.771 & 0.952 \\
\hline & & & & &
\end{tabular}


Adım 5: Gri ilişkisel katsayı matrisinin belirlenmesi

Alternatiflerin her biri için teker teker gri ilişki katsayısı bulunur.

$\gamma_{0 i}(j)=\frac{0+1(0.5)}{0.995+1(0.5)}=0.334$

şeklindeki hesaplama ile tüm alternatiflerin kriterlerine ait gri ilişkisel katsayılar hesaplanabilir. Gri ilişkisel katsayılar matrisi $(\gamma)$ :

$\gamma=\left[\begin{array}{lllll}0.334 & 0.333 & 0.333 & 0.333 & 0.339 \\ 0.348 & 0.373 & 0.368 & 0.371 & 0.381 \\ 0.579 & 0.624 & 0.518 & 0.599 & 0.502 \\ 0.914 & 0.894 & 1.000 & 0.896 & 1.000 \\ 0.651 & 1.000 & 0.846 & 1.000 & 0.718 \\ 0.333 & 0.336 & 0.338 & 0.336 & 0.334 \\ 0.349 & 0.336 & 0.339 & 0.337 & 0.333 \\ 0.364 & 0.365 & 0.364 & 0.366 & 0.359 \\ 0.348 & 0.342 & 0.346 & 0,343 & 0.334 \\ 0.335 & 0.339 & 0.338 & 0.339 & 0.335 \\ 1.000 & 0.683 & 0.697 & 0.689 & 0.520 \\ 0.338 & 0.346 & 0.343 & 0.345 & 0.377 \\ 0.452 & 0.382 & 0.399 & 0.389 & 0.336 \\ 0.366 & 0.345 & 0.351 & 0.347 & 0.334 \\ 0.365 & 0.354 & 0.359 & 0.357 & 0.337 \\ 0.384 & 0.379 & 0.378 & 0.379 & 0.389 \\ 0.450 & 0.449 & 0.440 & 0.451 & 0.433 \\ 0.482 & 0.386 & 0.407 & 0.393 & 0.344\end{array}\right]$

şeklindedir.

Adım 6: Gri ilişkisel derecelerin hesaplanması

Gri ilişki derece belirlenirken, kriterlerin önem derecelerinin eşit olduğu kabul edilerek her bir alternatife ait kriterlerin aritmetik ortalamasının alındığı formül uygulanmıştır.

$\Gamma_{01}=\frac{(0.334+0.333+0.333+0.333+0.339)}{5}=0.3344$

şeklindeki hesaplama ile tüm alternatiflerin gri ilişkisel dereceleri bulunmuş, sıralamaları yapılmış ve Tablo 6 'da verilmiştir.

Gri ilişkisel derecelendirme hesaplandıktan sonra katsayılar büyükten küçüğe doğru sıralanır. İlk sırada yer alan bireysel emeklilik şirketinin incelenen kriterlerle performansının en yüksek şirket olduğu yorumu yapılır. 
Tablo 6. Gri İlişkisel Dereceler ve Sıralamaları

\begin{tabular}{lcc}
\hline Alternatifler & Gri İlişkisel Derecelendirme & Siralama \\
\hline $\mathrm{A}_{1}$ & 0.3344 & 18. \\
$\mathrm{~A}_{2}$ & 0.3682 & 9. \\
$\mathrm{~A}_{3}$ & 0.5644 & 4. \\
$\mathrm{~A}_{4}$ & 0.9408 & 1. \\
$\mathrm{~A}_{5}$ & 0.8430 & 2. \\
$\mathrm{~A}_{6}$ & 0.3354 & 17. \\
$\mathrm{~A}_{7}$ & 0.3388 & 15. \\
$\mathrm{~A}_{8}$ & 0.3636 & 10. \\
$\mathrm{~A}_{9}$ & 0.3426 & 14. \\
$\mathrm{~A}_{10}$ & 0.3372 & 16. \\
$\mathrm{~A}_{11}$ & 0.7178 & 3. \\
$\mathrm{~A}_{12}$ & 0.3498 & 12. \\
$\mathrm{~A}_{13}$ & 0.3916 & 7. \\
$\mathrm{~A}_{14}$ & 0.3486 & 13. \\
$\mathrm{~A}_{15}$ & 0.3544 & 11. \\
$\mathrm{~A}_{16}$ & 0.3818 & 8. \\
$\mathrm{~A}_{17}$ & 0.4446 & 5. \\
$\mathrm{~A}_{18}$ & 0.4024 & \\
\hline
\end{tabular}

şeklinde hesaplamalar yapılmıştır.

\section{Tartışma, Sonuç ve Öneriler}

Araştırmadaki 18 bireysel emeklilik şirketinin katılımcı sayısı olarak performansı en iyi olan Garanti, daha sonra Anadolu ve Allianz hayat ve emeklilik şirketleridir. Performansı en düşük olanlar ise sirasiyla, Axa, Aegon, Fiba emeklilik ve hayat şirketleri gelmektedir.

Katılımcıların fon tutarı olarak performansları en iyi olan şirketler sırasıyla, Avivasa, Axa, Garanti emeklilik ve hayat şirketleridir. Performansı en düşük olanlar ise sirasıyla, Aegon, Axa, Bereket emeklilik ve hayat şirketleri gelmektedir.

Devlet katkısı fon tutarı olarak performansları en iyi olan şirketler sırasıyla, Anadolu, Avivasa, Garanti emeklilik ve hayat gelmektedir. Performansı en düşük olanlar ise sırasıyla, Aegon, Axa, Fiba emeklilik ve hayat gelmektedir. 
Katkı payı fon tutarı olarak performansları en iyi olan şirketler sırasıyla, Avivasa, Anadolu, Garanti emeklilik ve hayat gelmektedir. Performansı en düşük olanlar ise sırasıyla Aegon, Axa, Bereket emeklilik ve hayat şirketleri gelmektedir.

Emekli olan katılımcı sayısı olarak performansı en iyi olanlar ise sırasıyla, Anadolu, Avivasa, Garanti emeklilik ve hayat gelmektedir. Performansı en düşük olanlar ise sırasıyla, Bereket, Axa, Katılım emeklilik ve hayat gelmektedir.

$\mathrm{Bu}$ çalışmayı benzer çalışmalardan ayıran en önemli farklılık kullanılan kriterlerdir. Tezergil (2018) çalışmasında gider gelir tablolarını Akgül (2019) çalışmasında finansal oranları kullanarak performans değerlendirmeleri yapmışlardır. Söz konusu çalışmalarda kullanılan kriterler aynı birimle ifade edilmiştir. Oysa çok kriterli karar verme tekniklerinde kullanılan kriterlerin aynı birimle ifade edilmesi gibi bir şart bulunmamaktadır. Bu çalışmada kullanılan kriterlerin birimleri hem " $T L$ " olarak ifade edilen hem de "adet" olarak ifade edilen kriterlerden oluşturulmuştur. Bu konuda yapılan çalışmaların sonuçları ile bu çalışmanın sonuçlarında farklılıklar bulunmaktadır. Bu farklılıkların nedenleri, tercih edilen kriterler ve kullanılan zaman dilimleridir. Akgül (2019) çalışmasında kullanılan kriterler ile 2018 boyunca performans açısından sırasıyla en iyi ve en kötü şirket AVIVASA ve GÜNEŞ sigorta şirketi olarak belirtmiştir. Çalışma ile benzerliğine bakıldığında 2017 boyunca Avivasa şirketi katkı payı fon tutarı olarak performansı en iyi şirket olmuştur. Bu iki çalışmada aynı şirketin en iyi şirket olarak değerlendirilmesinde kullanılan kriterlerde ve tercih edilen zaman dilimlerinde farklılıklar bulunmaktadır.

$\mathrm{Bu}$ konuda ileride yapılacak çalışmalar için farklı çok kriterli karar verme teknikleri kullanılarak kıyaslama yapılabileceği önerilebilir.

\section{Kaynakça}

Akgül, Y. (2019). Borsa İstanbul'da işlem gören sigorta şirketlerinin finansal değerlerinin Gri İlişkisel Analizi. Uluslararası Turizm, İsletme, Ekonomi Dergisi, 3(1), 01-09.

Akpınar, S. \& Demirci, M.G. (2018). Zorunlu bireysel emeklilik sistemine geçiş ve yapılacak kesintilerin muhasebeleştirilmesi. Muhasebe ve Finansman Dergisi, 77(1), 137-146.

Aktaş, R. Doğanay, M.M. Gökmen, Y. Gazibey, Y. \& Türen, U. (2015). Sayısal karar verme yöntemleri, İstanbul: Beta Yayınları

Athawale, V.M. \& Chakraborty, S. (2011). Application of Grey Relational Analysis method in solving supplier selection problems. Int. Journal of Operations Management, 10(1).

Atıl̆̆an, M.H. (2018). Etkin bir bireysel emeklilik sistemi için öneriler. AÇÜ Uluslararası Sosyal Bilimler Dergisi, 4(1), 23-35.

Aydemir, E. Fevzi, B. \& Özdemir, G. (2013). Gri Sistem Teorisi ve uygulamaları: Bilimsel Yazın Taraması. Süleyman Demirel Üniversitesi İktisadi ve İdari Bilimler Fakültesi Dergisi (18), 187-200.

Aydın, A.E. \& Selçuk, E.A. (2017). Türkiye'de bireysel emeklilik sistemine katılım kararını etkileyen faktörler. Finans Politik \& Ekonomik Yorumlar, 54(1), 632.

Ayrıçay, Y. Özçalı, M. \& Kaya, A. (2013). Gri İlişkisel Analiz'in finansal kıyaslama aracı olarak kullanılması: İMKB-30 endeksindeki finansal olmayan firmalar üzerine bir uygulama. KSÜ Sosyal Bilimler Dergisi, 10(1), 201-238. 
Baş, M. \& Çakmak, Z. (2010). Gri İlişkisel Analiz ve lojistik regresyon analizi ile işletmelerde finansal başarısızlı̆ın belirlenmesi ve bir uygulama. Anadolu Üniversitesi Sosyal Bilimler Dergisi, 12(3), 63-82.

Baş, M. (2019). Gri İliş̧kisel Analiz ile finansal performans: BİST uygulaması. Journal of Social and Humanities Sciences Research, 6(42), 2780-2789.

Başdeğirmen, A. \& Işıldak, B. (2018). Ulaştırma sektöründe faaliyet gösteren işletmelerin performanslarının Gri İlişkisel Analiz ile değerlendirilmesi. Süleyman Demirel Üniversitesi İktisadi ve İdari Bilimler Fakültesi Dergisi, 23(2), 563-577.

Baştürk, F.H. Çakmak, D. \& Demirtaş, B. (2017), Sigortacılığa giriş, Ankara: Bankacıllk Akademisi Yayınları

Bektaş, H. \& Tuna, H. (2013). Borsa İstanbul gelişen işletmeler piyasasında işlem gören firmaların Gri İlişkisel Analiz ile performans ölçümü. Çankırı Karatekin Üniversitesi İktisadi ve İdari Bilimler Fakültesi Dergisi, 3(2), 185-198.

Bilge, T. Motorcu, A.R. \& Ivanov, A. (2017). Kompakt laminatın delinmesinde boyutsal tamlık için delme parametrelerinin Gri İlişkisel Analiz ile optimizasyonu. SDU International Journal of Technological Sciences, 9(2), 1-22.

Bülbül, S. E. \& Baykal, K. B. (2017). Hayat dışı branşlarda faaliyet gösteren Türk sigorta şirketlerinin finansal performans analizi: VIKOR Yönetimi. 3rd National Insurance and Actuarial Congress, Karabük.

Büyükgebiz, E. (2013). Ülke performanslarının Gri İlişkisel Analiz ile değerlendirilmesi. (Yüksek Lisans Tezi, Süleyman Demirel Üniversitesi, Isparta). Erişim adresi: http://tez2.yok.gov.tr/

Can, Y. \& Eyidiker, U. (2019). Bireysel emeklilik sisteminde otomatik katılımın Türkiye'de gelişiminin izlenmesi. Finans Ekonomi ve Sosyal Araştırmalar Dergisi, 4(4), 626-642.

Çakır, E. (2017). Kentsel dönüşüm kapsamında müteahhit firmanın SWARA-Gri İlişkisel Analiz yöntemiyle seçilmesi. The Journal Of International Scientific Researches, 2(6), 79-95.

Çetiner, M. \& Gündoğdu, F.K. (2018). Türkiye'de bireysel emeklilik ve emeklilik yatırım fonlarının görünümü: 2011-2017 dönemi. International Journal of Disciplines Economics \& Administrative Sciences Studies, 4(7), 24-34.

Çömlekçi, İ. \& Gökmen, O. (2017). Bireysel emeklilik sistemine katılmada etkili olan faktörler: TR42 bölgesinde bir araştırma. Uluslararası Sosyal Araştırmalar Dergisi, 10(49), 579-588.

Emeklilik Gözetim Merkezi, BES Temel Göstergeleri, 2019.

Gezen, A. \& Kalmış, H. (2019). Bireysel emeklilik yatırım fonlarının finansal performans analizi: Türkiye örneği. Social Sciences Studies Journal (SSSJournal), 5(35), 2563-2576.

Gülcan, N. (2017). Bireysel emeklilik sistemi farkındalığı: Üniversite öğrencilerine yönelik bir araştırma. Mehmet Akif Ersoy Üniversitesi Sosyal Bilimler Enstitüsü Dergisi, 9(2), 369-383.

Güleç, Ö.F. \& Özkan, A. (2018). Gri İlişkisel Analiz yöntemi ile finansal performansların değerlendirilmesi: BİST çimento şirketleri üzerine bir araştırma. Muhasebe ve Denetim Bakış, 54(2), 7796.

Gürol, B. \& Hazar, A. (2017). Türkiye'de faaliyet gösteren hayat dışı ve hayat emeklilik sigorta şirketlerinin performanslarının karşılaştırılması. 3rd National Insurance and Actuarial Congress, Karabük.

İskenderoğlu, Ö. Arslan, S. \& Çelik, M. S. (2019). Emeklilik yatırım fonlarının performanslarının karşılaştırmalı olarak incelenmesi: Türkiye örneği. İşletme Araştırmaları Dergisi, 11(3), 2114-2120.

Kaygın, C. Y. Bağcl, H. \& Tanır, D. (2019). BISTT Kobi sanayi şirketlerinin finansal performanslarının MW ve Gri İlişkisel Analiz yöntemleri ile ölçülmesi. KAÜİ̈BFD, 10(20), 944-965. 
Kırkağaç, M. \& Dalkılıç, N. (2017). Türkiye'de faaliyet gösteren emeklilik şirketlerinin performanslarının temel bileşenler analizi ve kümeleme analizi ile karşılaştırılması. 3rd National Insurance And Actuarial Congress, Karabük.

Köse, A. \& Türkel, U. (2017). Gri İlişkisel Analiz yöntemi ile hayat dişı branşlarda Türk sigorta sektörünün değerlendirilmesi. 3rd National Insurance And Actuarial Congress, Karabük.

Kurin, B.E. (2018). Türkiye' de bireysel emeklilik sistemi. İstanbul Barosu Dergisi, 92(6), 130-149.

Liu, S. \& Lin, Y. (2006). Grey Information: Theory And Pratical Applications With 60 Figures. Prited in The USA: Springer Science \& Business Media

Orakçı, E. \& Özdemir, A. (2017). Telafi edici çok kriterli karar verme yöntemleri ile Türkiye ve AB ülkelerinin insani gelişmişlik düzeylerinin belirlenmesi. AKÜ İ̈BF Dergisi, 19(1), 61-74.

Özbek, A. (2017). Çok kriterli karar verme yöntemleri ve EXCEL ile problem çözümü. Ankara: Seçkin Yayıncilik

Özdemir, A.İ. \& Deste, M. (2009). Gri İlişkisel Analiz ile çok kriterli tedarikçi seçimi: Otomotiv sektöründe bir uygulama. İstanbul Üniversitesi İşletme Fakültesi Dergisi, 38(2), 147-156.

Polat, A. \& Kekeç, H.M. (2017). Bireysel emeklilik sisteminin Türk vergi sistemi açısından analizi. Gazi Üniversitesi İktisadi ve İdari Bilimler Fakültesi Dergisi Gazi Akademi Genç Sosyal Bilimciler Sempozyumu Özel Sayısı, 175-191.

Sofyalıoğlu, Ç. (2011). Süreç hata modu etki analizini gri değerlendirme modeli. Ege Akademik Bakış, $11(1), 155-164$.

Şataf, C. \& Yıldırım, O. (2019). Türkiye' de bireysel emeklilik sisteminin (BES) algılanma düzeyi: Ordu ili örneği. Selçuk Üniversitesi Sosyal Bilimler Meslek Yüksekokulu Dergisi, 22(2), 572-588.

Tezergil, S. (2018). Portföy yönetim şirketlerinin finansal performanslarının Gri İlişkisel Analiz yöntemi ile değerlendirilmesi, Yüzüncü Yıl Üniversitesi Sosyal Bilimler Enstitüsü Dergisi, 39(1), 245-262.

T.C. Başbakanlık Hazine Müsteşarlığı, Sigortacılık ve Özel Emeklilik Raporları, 2016.

Tsai, C.U. Chang, C.L. \& Chan, L. (2003). Applying Grey Relational Analysis to the venter evaluation model. The Internet and Management, 11(3), 45-53.

Uçkun, N. \& Girginer, N. (2011). Türkiye'deki kamu ve özel bankaların performanslarının Gri İlişki Analizi ile incelenmesi. Akdeniz Üniversitesi İktisadi ve İdari Bilimler Fakültesi Dergisi, 11(21), 46-66.

Uğur, L.O. \& Baykan, U.N. (2017). Konut satın alma kararı verilmesinde Gri İlişkisel Analiz tekniği uygulaması. Düzce Üniversitesi Bilim ve Teknoloji Dergisi, 5(7), 220-230.

Wu, H.H. (2002). A Comparative study of using Grey Relational Analysis in multiple attribute decision making problems. Quality Engineering, 15(2), 209-217.

Yıldırım, B.F. \& Önder, E. (2015). Çok kriterli karar verme yöntemleri. Bursa: Dora Yayınları

Yumurtac1, B. \& Onursal, F.S. (2019). Kısıtlar teorisi düşünce süreçleri ile bireylerin bireysel emeklilik sisteminden ayrılma nedenlerinin analizi. İşletme Araştırmaları Dergisi, 11(4), 3269-3282.

Zhai, L.Y. Khoo, L.P. \& Zhang, Z.W. (2009). Design concept evaluation in product development using rough sets and Grey Relation Analysis. Expert System with Applications, 36, 7072-7079. 